\title{
Estratégia de posicionamento da marca: estudo da relação da proteção do meio ambiente com o marketing social
}

\author{
Brand positioning strategy: a study of the relationship of \\ environmental protection with social marketing
}

Hernan Edgardo Contreras Alday ${ }^{[a]}$, José Antonio Arantes Salles ${ }^{[b]}$

[a] Doutor em Engenharia de Produção pela Universidade Metodista de Piracicaba (UNIMEP), professor da Fundação Escola de Sociologia e Política de São Paulo (FESPSP), São Paulo, SP - Brasil, e-mail: hernanc@terra.com.br

[b] Doutor em Administração de Empresas pela Fundação Getúlio Vargas (FGV), professor da Universidade Nove de Julho

(UNINOVE), São Paulo, SP - Brasil, e-mail: jasalles@terra.com.br

\section{Resumo}

0 objetivo desta pesquisa consistiu em verificar a relação da proteção da natureza e o meio ambiente com o marketing social na empresa 0 Boticário, visando o posicionamento da marca. Este estudo foi caracterizado como estudo de caso, sendo que os dados foram coletados através da análise documental disponível e aplicação de entrevistas. A lógica de tratamento dos dados é qualitativa, uma vez que se utilizou a análise documental para caracterizar as categorias analíticas em estudo e estabelecer as relações. Os dados coletados revelaram que as categorias de grupos, funcionários das lojas, grupos de clientes que habitualmente compram os produtos da marca, e pessoas que não são clientes ou que compram esporadicamente os produtos de 0 Boticário encontram-se muito convergentes nas suas percepções em relação à influência dos programas de marketing social associados à preservação da natureza e ao meio ambiente na empresa em estudo.

Palavras-chave: Estratégia. Natureza. Meio ambiente. Marketing social.

\begin{abstract}
The objective of this research was to investigate the relationship of protecting nature and the environment with the social marketing in the $O$ Boticario company, aimed at positioning the brand. This study was featured as a case study, and the data were collected through document analysis and application available for interviews. The logic of processing the data is qualitative, since the document analysis was used to characterize the analytical study and establish relationships. The data collected revealed that the categories of groups, store employees, groups of customers who usually buy branded products, and people who are not customers or buying products sporadically o Boticario, are very convergent in their perceptions regarding the influence of social marketing programs associated with the preservation of nature and the environment, the company under study.
\end{abstract}

Keywords: Strategy. Nature. Environment. Social marketing. 


\section{Introdução}

As empresas são importantes agentes de promoção do desenvolvimento econômico e do avanço tecnológico que está transformando rapidamente a consciência global. Egri et al. (2004) consideram fundamental que exista um processo de desenvolvimento que coloque como meta a preservação do meio ambiente, do patrimônio cultural, a promoção dos direitos humanos, e a construção de uma sociedade economicamente próspera e socialmente justa, dado que os diversos setores da sociedade estão redefinindo seus papéis e as organizações estão aumentando as expectativas em relação às práticas de responsabilidade social nas organizações (BROWN; FRASER, 2004).

As empresas, segundo Stingson (1999), adotando um comportamento socialmente responsável, são poderosas agentes de mudança para, juntamente com Estados e sociedade civil, construir um mundo melhor. A responsabilidade social está se tornando cada vez mais um fator de sucesso empresarial e isso abre novas perspectivas para a construção de um mundo economicamente mais próspero e socialmente mais justo. Destaca-se também a importância de que a utilização das ferramentas de marketing, mais especificamente marketing social, segundo Barach (1984), não se restringe a um tipo específico de organização.

Sirgy et al. (1985) verificaram que as marcas possuem valor não só para clientes como para investidores, e são negociadas no mercado. Seu valor inclui várias dimensões, como desempenho, imagem social, valor, fidelidade e identificação. Por exemplo, muitas pesquisas confirmam que os consumidores preferem comprar produtos de países industrializados devido ao valor da marca-país (ROTHSCHILD; ANDREASEN, 1998).

Assim, o objetivo desta pesquisa constitui em verificar a relação da proteção da natureza e o meio ambiente com o marketing social na empresa 0 Boticário, identificando qual é o principal programa de responsabilidade social na empresa, visando o posicionamento da marca.

\section{Revisão da literatura}

0 marketing social pode parecer uma das ideias mais recentes em termos de práticas voltadas à saúde pública e serviços humanos, mas, na verdade, marketing social não é tão novo. Kotler e Zaltman (1973) utilizaram pela primeira vez a expressão "marketing social" em 1971, descrevendo-o como sendo o processo de criação, implementação e controle de programas para influenciar a aceitabilidade de ideias sociais.

Nesse mesmo sentido, Kotler (1998) afirma que o marketing social sustenta que a organização deve determinar as necessidades e desejos e interesses dos mercados-alvo, e então proporcionar aos clientes um valor superior, de forma a manter ou melhorar o bem-estar da sociedade. Também segundo este novo conceito de marketing social, o conceito tradicional de marketing não percebe os possíveis conflitos entre os desejos de curto prazo dos consumidores e seu bem-estar no longo prazo. Kotler e Amstrong (1995) consideram que o conceito de marketing social exige que os profissionais de marketing equilibrem três fatores ao definirem sua política de mercado: os lucros da empresa, os desejos dos consumidores e os interesses da sociedade.

Outra definição é a de Churchill e Peter (2000), que consideram que o marketing de causa é o marketing destinado a criar apoio para ideias e questões ou a levar as pessoas a mudar os comportamentos socialmente indesejáveis. Numa outra interpretação, Schiavo (1999) defende que marketing social é a gestão estratégica do processo de mudança social a partir da adoção de novos comportamentos, atitudes e práticas, nos âmbitos individual e coletivo, orientadas por preceito ético, e fundamentadas nos direitos humanos e na equidade social.

Chama a atenção que, nas conceituações aqui colocadas, o elemento transformador é um dos objetivos desse campo. No Brasil, porém, o termo "marketing social" está sendo utilizado, segundo Weinreich (1999), especialmente pela mídia, para designar atuação empresarial no campo social com o objetivo de obter diferenciais competitivos, sem que essas ações tenham o objetivo de influenciar em um comportamento coletivo. Para Varadorajan e Menon (1988), o uso do marketing social é um programa que procura alcançar dois objetivos: melhorar a performance organizacional e colaborar com causas sociais.

Richers (2000) insere nesse contexto que é o marketing comunitário, que envolveria marketing social, marketing cultural e marketing ecológico, os quais, segundo ele, apelam para aquilo que o indivíduo valoriza acima e além do consumo de bens. A partir dos anos 80 , algumas empresas passaram a descobrir que, com as mesmas ferramentas de marketing utilizadas para aumentar vendas, poderiam também promover um serviço público e, ainda mais, que os dois objetivos poderiam ser complementares (EISMAN, 1992). 
Porter (1980) identificou que o posicionamento é a arte de configurar a imagem da empresa e o valor oferecido do produto em cada segmento de mercado, de forma que os clientes possam entender e apreciar o que a empresa proporciona em relação à concorrência; entre outros aspectos, as marcas no conceito de Cobra (1990) também passam a ser elementos muito importantes no posicionamento de uma empresa.

0 marketing social pode ser definido como uma ferramenta estratégica de marketing e de posicionamento que associa uma empresa ou marca a uma questão ou causa social relevante, em benefício mútuo, verificado por Cadbury (1996 apud PRINGLE; THOMPSON, 2000), observando que o marketing social é uma forma efetiva de melhorar a imagem corporativa, diferenciando produtos e aumentando tanto as vendas quanto a fidelidade.

0 posicionamento pode ser utilizado por uma empresa como elemento de formulação estratégica, desde que leve em consideração: (1) a percepção do posicionamento de seus produtos nos respectivos segmentos de mercado; (2) uma análise, em cada segmento de mercado, da situação da empresa e concorrência (COBRA, 1990). As empresas utilizam estratégias de posicionamento para distinguir seus serviços dos serviços dos concorrentes e para projetar comunicações que transmitam sua posição desejada (LOVELOCK, 2001).

Andreasen (1996) considera que é possível identificar diferentes tipos de estratégias de marketing relacionado a uma causa, que pode acontecer através da destinação de um percentual sobre as vendas de um certo produto, da distribuição conjunta de produtos ou informações sobre determinada questão, ou do licenciamento de uma marca ou logotipo para alguma empresa comercializar.

A filantropia estratégica é uma prática que vem crescendo com sucesso. A responsabilidade social, em estudos de Black e Härtel (2004), foi considerada como uma forma de gestão empresarial que envolve a ética em todas as atitudes. Significa fazer todas as atividades da empresa e promover todas as relações - com seus funcionários, fornecedores, clientes, com o mercado, o governo, com o meio ambiente e com a comunidade - de uma forma socialmente responsável.

Assim, a responsabilidade social de uma empresa pode ser totalmente compatível com o conceito de marketing. Etzel et al. (2001) verificaram que a compatibilidade depende de duas coisas: quão amplamente uma empresa percebe os seus objetivos de marketing e quanto tempo ela pretende esperar para atingir seus objetivos.

Na opinião de Varadorajan e Menon (1988), cabe ao marketing a tarefa de realizar o ajustamento entre o produto específico que a empresa oferece e algum grupo de consumidores do mercado. Tal tarefa deve ser permanente no mercado, a saber: (a) mudanças no ambiente; (b) mudanças no comportamento do consumidor e (c) mudanças na ação dos concorrentes. As comunicações de marketing podem ser interpretadas como uma tentativa da organização de projetar sua imagem idealizada para o público interno e externo, mas que, na verdade, uma empresa não tem uma simples imagem, ao contrário, tem várias imagens. Nesse sentido, Trout e Rivkin (1996) afirmam que o campo de batalha final de marketing é a mente; quanto melhor você compreender como funciona a mente, melhor vai compreender como funciona o posicionamento. Neste ponto de vista, a imagem de uma empresa é formada a partir de atributos de duas modalidades básicas: (a) habilidades da empresa e (b) responsabilidade social.

\section{Metodologia}

O estudo foi exploratório seguindo a classificação quanto aos objetivos específicos, com abordagem qualitativa (GOODE; HATT, 1969), buscando-se respostas para as questões de pesquisas que foram levantadas. A estratégia utilizada foi o estudo de caso que, segundo Schramm (1971 apud YIN, 1983), apresentou as principais fontes de evidências. Neste estudo optou-se pela entrevista do tipo focal semiestruturada e individual, como técnica de coleta de dados realizada junto aos atores, sujeitos desta pesquisa, por um curto período de tempo (em torno de 1 hora) (MERTON et al., 1990). A amostragem foi intencional, considerando os funcionários-chave que poderiam contribuir com as informações para esta pesquisa. 0 corte foi transversal, considerando a periodicidade segundo Hair Junior et al. (2005).

0 motivo básico deste trabalho é verificar a percepção e o entendimento dos grupos de análise escolhidos quanto à associação dos programas de proteção da natureza e o meio ambiente com o marketing social, visando o posicionamento da marca. Assim, o presente estudo pretende responder às seguintes perguntas de pesquisa: (1) Qual é o principal programa social aplicado pela empresa? (2) Qual é a relação 
do principal programa social implantado pela empresa com a marca dos produtos comercializados? (3) Qual é a relação do principal programa social da empresa com a marca da própria organização? (4) Qual é a principal estratégia da empresa em relação ao posicionamento da sua marca?

A escolha da empresa 0 Boticário teve uma grande importância, pois se trata de uma empresa que é referência nacional na implementação de programas sociais, bem como uma referência nacional e internacional no processo de comercialização de produtos através do sistema de franquias. 0 propósito da escolha de 0 Boticário foi obter um diferencial a mais no processo de implementação de programas de responsabilidade social. 0 modelo participativo e estruturado permite a definição de ações estratégicas com foco para o negócio principal da organização (TACHIZAWA et al., 2001).

0 universo desta pesquisa abrange os funcionários das lojas, os clientes e os não clientes. 0 primeiro grupo é constituído por funcionários das lojas $\mathrm{O}$ Boticário localizadas em Curitiba e Região Metropolitana; o segundo grupo é constituído por clientes que habitualmente compram os produtos de 0 Boticário; e o terceiro grupo é constituído por pessoas que não são clientes ou que compram apenas esporadicamente produtos da marca. Chegou-se a um critério de representatividade legítima em termos de participação nos processos foco do presente estudo, não tendo, portanto, nenhuma relação numérica com amostras quantitativas. No entanto, a amostra foi de 35 (trinta e cinco) atores que, para um tratamento de dados qualitativos, é aceitável (COLWELL, 1990).

Nesta pesquisa, os dados foram coletados durante um período intensivo de 60 dias, por meio de visitas sistemáticas às lojas selecionadas, a fim de abordar os integrantes dos três grupos participantes do estudo. As entrevistas foram espontâneas assumindo o caráter de uma conversa informal, mas seguindo um certo conjunto de perguntas que se originam do protocolo de estudo de caso. Esta pesquisa pode ser considerada um procedimento formal com método de pensamento reflexivo que requer um tratamento científico e se constitui no caminho para se conhecer a realidade ou para descobrir verdades parciais (MORGAN; SMIRCICH, 1980).

0 método de análise utilizado de estudo de caso (EINSENHARDT, 1989) considera quatro técnicas analíticas dominantes: adequação ao padrão, construção da explanação, análise de séries temporais e modelos lógicos de programa.

\section{Apresentação e análise dos dados}

Neste capítulo são apresentadas, no primeiro momento, as características do programa de responsabilidade social da empresa 0 Boticário. Em seguida, é apresentada a caracterização e análise dos grupos envolvidos na pesquisa, quais sejam: o grupo integrado pelos funcionários das lojas da empresa, o grupo integrado pelos clientes que habitualmente compram os produtos da marca, e o grupo dos clientes que não compram os produtos da marca 0 Boticário.

Apresentação do programa de responsabilidade social

A Fundação 0 Boticário de Proteção à Natureza é uma organização sem fins lucrativos, criada e mantida pelo grupo 0 Boticário, sendo seu objetivo a promoção e realização de ações de conservação da natureza. A Fundação O Boticário concretiza seus ideais por intermédio do incentivo a iniciativas de proteção e pesquisa de conservação da natureza, pela efetiva proteção do ambiente natural e pela educação e mobilização das pessoas para a conservação da natureza.

Para contribuir ainda mais efetivamente para a preservação de locais de relevante significado ecológico, a Fundação 0 Boticário desenvolve um importante trabalho por meio do Programa de Áreas Naturais Protegidas. Este programa tem como objetivos criar reservas próprias para proteger significativos remanescentes de nossos biomas para a humanidade, incentivar outros cidadãos e organizações a seguirem este exemplo e ainda compilar dados e informações sobre áreas protegidas para subsidiar o entendimento e ações para o gerenciamento e a proteção dessas áreas.

O exemplo mais conhecido do trabalho da Fundação O Boticário nessa linha é a criação e manutenção da Reserva Natural Salto Morato, considerada Sítio do Patrimônio Natural da Humanidade pela UNESCO, título raro entre unidades de conservação privadas.

o Centro de Capacitação em Conservação da Biodiversidade, idealizado pela Fundação O Boticário de Proteção à Natureza e implantado na Reserva Natural Salto Morato, tem por objetivo difundir princípios e técnicas de conservação da biodiversidade para interessados de todo o Brasil, além de promover oficinas para moradores da região, visando à criação de alternativas econômicas para a população local.

Hoje, somam-se 47 cursos realizados e mais de 1200 participantes ligados a 150 diferentes instituições de 
93 municípios e 24 estados brasileiros. 0 Centro de Capacitação em Conservação da Biodiversidade mantém-se atualmente com recursos próprios da Fundação 0 Boticário e de patrocinadores, além de oferecer cursos e oficinas, e cursos de Pós-Graduação já ministrados pela fundação 0 Boticário.

\section{Caracterização e análise dos grupos envolvidos na pesquisa}

O primeiro grupo, composto por dez funcionários das lojas da empresa, de Curitiba e Região Metropolitana, respondeu às perguntas de pesquisa, de forma categórica, que o principal programa de responsabilidade social é a preservação da natureza e o meio ambiente, através da Fundação 0 Boticário, criada especialmente com essa finalidade. Este grupo considera, também, que existe uma total relação desse programa de preservação da natureza e o meio ambiente com a marca dos produtos e até com a marca da própria empresa, que representa uma associação natural com o conceito que ela divulga. No entanto, os integrantes não manifestaram de maneira geral se representava uma estratégia de posicionamento alegando não ter conhecimento das estratégias da empresa. Do ponto de vista dos benefícios esperados com esse programa, o grupo percebe que o fato de trabalhar em uma empresa que mantém e financia um programa de preservação da natureza e o meio ambiente, associado à marca dos produtos e da própria empresa, passa a ser um ganho adicional em termos de status e de interesse pessoal, até como argumento para a venda dos produtos da marca. Alguns citaram o interesse pessoal de poder participar no programa de alguma forma.

O segundo grupo, integrado por quinze clientes que habitualmente compram os produtos 0 Boticário, sente-se atraído pela ligação direta que existe entre os produtos consumidos e a própria natureza, manifestando que a proposta da empresa acaba conquistando o interesse dos clientes que não apenas compram os produtos da marca, mas permanecem fiéis a eles no seu consumo habitual. Neste grupo também se encontram pessoas que participam dos clubes de clientes, alguns já cadastrados, que mostram assim sua satisfação pela marca. Como benefício direto, este grupo de clientes habituais valoriza a permanente e contínua comunicação e "assessoramento" que a empresa fornece através dos clubes de relacionamento, tais como "Garota Thaty", "Amiga Ma Chéri” e o "Clube
Boti", os quais foram especialmente projetados para as crianças e adolescentes. 0 "Programa Fidelidade", criado em 2000, considera a participação dos clientes para a seleção dos produtos que serão oferecidos e são tratados como importantes parceiros.

0 terceiro grupo, composto de dez pessoas que não compram os produtos da marca 0 Boticário, ou compram de forma muito esporádica, afirmou seu reconhecimento da associação dos produtos da marca com a natureza, considera que as campanhas veiculadas pela mídia ajudam a fixar esse posicionamento. No entanto, os integrantes não poderiam afirmar tratar-se de uma estratégia de posicionamento, até porque há outras empresas que também praticam e implantam esses programas. Um benefício apontado por algumas pessoas que responderam à pesquisa foi a satisfação de comprar produtos de uma marca que respeita a natureza, porém esses mesmos compradores não acreditam que exista ainda no país uma consciência dos empresários nesse sentido. Alguns deles chegaram a expressar a sua desconfiança, no sentido que poderia ser apenas mais um argumento de vendas. Por outro lado, essa consciência do consumidor tem uma relação direta com a educação do povo que, em último termo, poderá rejeitar os produtos que não respeitam o meio ambiente, participando até de campanhas contra determinadas marcas. 0 contrário também é verdadeiro, se de fato determinadas marcas oferecem produtos que respeitam a natureza, os consumidores serão os primeiros a preferir o seu consumo.

\section{Discussão dos resultados}

Constatou-se a grande importância e status que alguns programas sociais assumiram na empresa e, principalmente, na consciência e espírito dos seus funcionários. Considerando que o grande foco é a preservação da natureza e o respeito pelo meio ambiente, toda e qualquer ação nesse sentido adquire uma importância vital no direcionamento das ações empresariais e sua associação com a imagem da companhia.

Os resultados obtidos com a pesquisa, a partir da análise dos dados, mostram que existe um grande reconhecimento por parte dos dois primeiros grupos, da associação do marketing social com o posicionamento da empresa. 0 terceiro grupo, de não clientes ou clientes esporádicos, mostra uma certa desconfiança no sentido da existência real do que se divulga nas campanhas publicitárias, o que pode ser considerado 
perfeitamente normal num processo de lançamento de tantos produtos, nos mais diversos setores da economia, com apelos nem sempre verdadeiros.

\section{Conclusões e recomendações}

Uma das principais conclusões neste trabalho é reconhecer que o estudo de caso realizado na empresa 0 Boticário mostra uma empresa com características diferenciadas em relação à implementação de programas e ações de responsabilidade social.

0 primeiro passo, na maioria das vezes, são programas orientados para benefícios dos seus funcionários. Nesse sentido, deve-se diferenciar ações que a lei obriga, que constitui o básico que uma empresa deve cumprir, e que de fato muitas organizações não cumprem.

Um segundo passo é representado pela extensão de benefícios não obrigatórios, como educação, alimentação, serviços médicos e outros, que ficam a critério da empresa. 0 marketing social tem por objetivo modificar as atitudes ou comportamentos do mercado-alvo, tendo como principal meta o atendimento dos interesses desse mercado ou da sociedade, cuja obtenção se dá através da concretização de ideias e serviços.

Muitas das ações de marketing social não são conhecidas pelo público interno, o que foi observado na pesquisa junto ao grupo dos funcionários das lojas que participaram do estudo, tendo dificuldades para perceber que se trata de uma estratégia de posicionamento que, associada com a marca, pode representar alguma vantagem competitiva.

Certamente, sendo seu principal foco a preservação da natureza e meio ambiente, é razoável pensar que os outros programas em andamento, embora tenham uma importância relativa para a organização, mas que não têm relação com o foco principal da empresa, possam ficar um pouco restritos em termos de desenvolvimento e divulgação.

No entanto, para o sucesso futuro da organização, seria conveniente não deixar apenas por conta da percepção do consumidor atual, porque as novas gerações poderão não perceber essa associação de imagem com a marca 0 Boticário.

Assim, a aplicação dos conceitos de marketing social, no sentido de evidenciar melhor as ações desenvolvidas e em desenvolvimento através de campanhas de divulgação mais explícitas direcionadas para os diferentes públicos - interno, franqueados e consumidor em geral, poderá gerar uma maior sinergia em relação aos produtos oferecidos pela empresa, em relação à filosofia de empresa responsável socialmente e em relação ao seu posicionamento de maneira geral nos mercados onde atua e/ou pretende atuar.

Alguns entrevistados citaram a questão de sobrevivência das empresas, não apenas se conformando com os métodos tradicionais de marketing. Outros lembraram a tendência do mercado, no sentido de que as empresas que não desenvolvem programas de responsabilidade social e não realizam investimentos no marketing social, simplesmente estarão fora do mercado, conceito emitido principalmente pelos integrantes do grupo dos clientes que habitualmente compram produtos da marca.

Em face destas constatações, entende-se como relevante a aplicação de novas pesquisas que possibilitem a ampliação da compreensão do tema e do conhecimento da empresa objeto do estudo, bem como de outras organizações. Neste sentido, são recomendadas algumas ações que visem: (1) investigar a influência que as empresas que implementam programas de responsabilidade social e os utilizam como estratégia de posicionamento, como 0 Boticário, exercem sobre outras empresas que ainda não adotam esses programas; (2) investigar, de forma mais aprofundada, a relação das ações do marketing social com os resultados da empresa; (3) verificar a conveniência de se ter estratégias específicas para os programas de responsabilidade social, através do marketing social.

\section{Referências}

ANDREASEN, A. R. Profits for nonprofits: find a corporate partner. Harvard Business Review, v. 74, n. 6, p. 47-59, 1996.

BARACH, J. A. Applying marketing principles to social causes. Business Horizons, v. 27, n. 4, p. 65-69, 1984.

BLACK, L. D.; HÄRTEL, C. E. J. The five capabilities of socially responsible companies. Journal of Public Affairs, v. 4, n. 2, p. 125-144, 2004.

BROWN, J.; FRASER, M. Social and environmental accounting: how are you approaching it? Chartered Accountants Journal, v. 83, n. 8, p. 16-20, 2004.

CHURCHILL, G. A.; PETER, J. P. Marketing: criando valor para os clientes. São Paulo: Saraiva, 2000. 
COBRA, M. H. N. Administração de marketing. São Paulo: Atlas, 1990.

COLWELL, J. Qualitative market research: a conceptual analysis and review of practitioner criteria. Journal of the Market Research Society, v. 32, n. 1, p. 13-36, 1990.

EGRI, C. P. et al. Managerial perspectives on corporate environmental and social responsibilities in 22 countries. In: ACADEMY OF MANAGEMENT ANNUAL MEETING, 2004. New Orleans. Annals... New Orleans: Academy of Management, 2004.

EINSENHARDT. K. M. Building theories from case study research. Academy of Management Review, v. 14, n. 4, p. 532$550,1989$.

EISMAN, R. Sweet charity. Incetive, p. 24-29, 1992.

ETZEL, M. J. et al. Marketing. São Paulo: Makron Books, 2001.

GOODE, W. J.; HATT, P. K. Métodos em pesquisa social. São Paulo: Nacional, 1969.

HAIR JUNIOR, J. F. et al. Fundamentos e métodos de pesquisa em administração. Porto Alegre: Bookman, 2005.

KOTLER, P.; AMSTRONG, G. Princípios de marketing. 7. ed. Rio de Janeiro: Prentice Hall, 1995.

KOTLER, P. Administração de marketing: análise, planejamento, implementação e controle. 5. ed. São Paulo: Atlas, 1998.

KOTLER, P.; ZALTMAN, G. Social marketing: an approach to planned social change. In: LAZER, W.; KELLEY E. J. Social marketing: perspectives and viewpoints. Homewood: R. D. Irwin, 1973.

LOVELOCK, C. Serviços: marketing e gestão. São Paulo: Saraiva, 2001.

MERTON, R. K.; FISKE, M.; KENDALL, P. L. The focused interview: a manual problems and procedures. 2 nd. ed. New York: Free Press, 1990.

MORGAN, G.; SMIRCICH, L. The case for qualitative research. Academy of Management Review, v. 5, n. 4, p. 491-500, 1980.

PORTER, M. Competitive strategy: techniques for analyzing industries and competitors. New York: Free Press, 1980.
PRINGLE, H.; THOMPSON M. Marketing social: marketing para causas sociais e a construção das marcas. São Paulo: Makron Books, 2000.

RICHERS, R. O despertar do marketing comunitário. Conjuntura Social, v. 2, n. 3, p. 47-50, 2000.

ROTHSCHILD, M.; ANDREASEN, A. Considering social marketing from the perspective of several consumer research paradigms. Advances in Consumer Research, v. 25, p. 295298, 1998.

SCHIAVO, M. R. Conceito e evolução do marketing social. Conjuntura Social, v. 1, n. 1, p. 25-9, 1999.

SIRGY, M. et al. The question of value in social marketing: use of quality-of-life theory to achieve long-term life satisfaction. American Journal of Economics and Sociology, v. 44, n. 2, p. 215-228, 1985.

STINGSON, B. Sustainable development for industry and society. Building Research \& Information, v. 27, n. 6, p. 424$430,1999$.

TACHIZAWA, T.; CRUZ, J. B.; ROCHA, J. A. de O. Gestão de negócios: visões e dimensões empresariais da organização. São Paulo: Atlas, 2001.

TROUT, J.; RIVKIN, S. 0 novo posicionamento: a última palavra sobre estratégia de negócios no mundo. São Paulo: Makron Books, 1996.

VARADORAJAN, P. R.; MENON, A. Cause related marketing: a co aliment of marketing strategy and corporate philantropy. Journal of Marketing, v. 52, n. 3, p. 58-74, 1988.

WEINREICH, N. K. What is Social Marketing? 1999. Disponível em: <http://www.social-marketing.com/whatis. html>. Acesso em: 20 set. 2011.

YIN, R. K. The case study method: an annotated bibliography. Washington, D.C.: Cosmos Corporation, 1983.

Recebido: 26/09/2011

Received: 09/26/2011

Aprovado: $12 / 10 / 2011$

Approved: 10/12/2011 